Proc. of the X Int. Conf. - Ion Implantation and other Applications of Ions and Electrons, Kazimierz Dolny 2014

\title{
Influence of Temperature on Electrical Parameters of GaAs in the Aspect of Applications in Photovoltaics
}

\author{
P. WEGIEREK* AND P. BILlEWICZ \\ Lublin University of Technology, Nadbystrzycka 38A, 20-618 Lublin, Poland
}

\begin{abstract}
The article describes the results of the research on thermal stability of electrical parameters of $n$-type gallium arsenide doped with tellurium, defected by ion implantation, measured at the operating temperature ranging from $77 \mathrm{~K}$ to $373 \mathrm{~K}$. The aim of the work is to investigate the character of changes in the values of such electrical parameters as resistivity, capacity and loss tangent of the tested GaAs samples, exposed to different thermal conditions. Temperature dependences analyzed in the paper could be taken as a basis to formulate general speculations concerning potential applications of the tested material as a substrate in the process of photovoltaic cells production. The phenomenon of conversion of solar energy into electricity is strongly connected with electrical properties of photovoltaic cell substrate material and its internal structure. Moreover, the efficiency of photoconversion is affected by such factors as charge carrier lifetime distribution and diffusion length in the base material. Therefore, it is necessary to confirm what is the character of the influence of operating temperature on the electrical parameters of GaAs and what modification could be introduced in the material in order to increase the efficiency of photoconversion.
\end{abstract}

DOI: $10.12693 /$ APhysPolA.128.875

PACS: 61.72.uj, 61.72.Cc, 72.80.Ey

\section{Introduction}

It is commonly known that many types of photovoltaic (PV) panels and technologies of their production are currently available on the commercial market. In the last decade it was possible to notice a thriving development of this branch of industry, especially a trend to continual searching for new materials and production methods, aimed primarily at improving the efficiency and reducing the price of the PV cells. The most common and most popular material used in the production of photovoltaic cells is silicon, because of such advantages as low price, widespread accessibility and high stability of crystal structures. According to the latest report of U.S. National Renewable Energy Laboratory on the best research-cell efficiencies [1] maximum efficiency of the single crystal silicon photovoltaic cells reaches the level of $25 \%$. However, the reported values were recorded in the laboratory conditions and could be significantly different compared to the ones that could be possibly obtained in the real operating environment.

On the other hand, the same report indicates the gallium arsenide as the material that enables to substantially increase the efficiency of PV cells up to the $44.7 \%$. For that reason many authors of recent publications in the field of photovoltaic science, commonly undertake research aimed at improving characteristics of photovoltaic cells constructed on the basis of gallium arsenide and enhancing their production process, which is still relatively expensive. In Ref. [2] the author stressed strong influence of temperature on the parameters of PV cells. Particularly, open circuit voltage significantly decreases with

${ }^{*}$ corresponding author; e-mail: p.wegierek@pollub.pl temperature, whereas the increase in short circuit current value is very slow. Consequently, other parameters like maximum power, fill factor and efficiency, also decrease significantly with the increase in temperature. Simultaneously, the authors of $[3,4]$ pointed out to a number of methods which allow to rise the efficiency of PV cells. Among the suggested improvements there are such solutions as: introduction of more advanced production technology, reduction of reflections by using anti-reflective coatings, decreasing absorption surface temperature by cooling systems, maximizing the usage of a free space between single cells, implementation of solar radiation concentrators and introducing changes in the material which a cell is made of. Application of the last mentioned solution results in the increase of a cell efficiency by 1.4 times for multicrystalline silicon, 1.8 times for monocrystalline silicon, 2.2 times for GaAs photovoltaic cell, 2.3 times for cell made of $\mathrm{GaAs} / \mathrm{GaAsAl}$ and 2.85 for the $\mathrm{AlGaAs} / \mathrm{Si}$ cell. The role of ion implantation technology in solar cell substrates manufacturing process was also discussed in [5]. On the other hand, in the papers $[6,7]$ the influence of proton implantation and post-implantation annealing on the physical properties of GaAs substrate has been explained.

What is more, in $[8,9]$ it has been shown that singlecrystal, thin film GaAs PV modules have achieved higher efficiencies than their polycrystalline and amorphous counterparts. In addition, authors of $[10,11]$ reported that low cost manufacturing processes are being developed by reusing the single-crystal substrates. Additionally, announcing the results of the experimental measurements, the authors of [12] concluded that the recently tested non-concentrator GaAs PV module operates with the efficiency level which is close to the theoretical limit and it is expected to be less sensitive to the influence of the operating temperature. 
Taking into consideration the state of the art described above, it is therefore justified to perform experimental verification of the influence of temperature on the electrical parameters of the GaAs substrate which is used in the PV cells production process. The superior objective of such investigation is to confirm whether the hydrogenimplanted GaAs substrate represents considerable value for PV cells production purposes.

\section{Experiment}

The main purpose of the performed experiment was to determine optimal implantation and post-implantation treatment conditions in order to achieve maximum stability of the measured values of resistivity $\rho$, capacity $C$ and loss tangent $\tan \delta$ in the function of the operating temperature $T_{\mathrm{p}}$ and annealing temperature $T_{\mathrm{a}}$. The experiment has been carried out in accordance with the methodology described in [13]. As the object of research several samples of GaAs doped with tellurium of the resistivity $\rho=(0.55 \pm 0.05) \Omega \mathrm{cm}$ were chosen. In order to obtain regular distribution of dopant the tested samples were subjected to poly-energy implantation of $\mathrm{H}^{+}$ions of the energies $E=65,130,220,300$, and $400 \mathrm{keV}$ and the respective fluences $D=1.0 \times 10^{14}, 1.1 \times 10^{14}$, $1.2 \times 10^{14}, 1.5 \times 10^{14}$ and $2.0 \times 10^{14} \mathrm{~cm}^{-2}$. The measurements were made in the operating temperature range from $173 \mathrm{~K}$ to $373 \mathrm{~K}$. During the experiment the samples were isochronously annealed for $15 \mathrm{~min}$, within the range of annealing temperatures $T_{\mathrm{a}}$ up to $663 \mathrm{~K}$, with average increments of $(20 \div 40) \mathrm{K}$. Implantations were made at room temperature, using the implanter with the ion source described in [14-18]. Initial sample parameters as well as implantation conditions and annealing temperature were determined on the basis of previously carried out research, described in [19, 20].

\section{Analysis of the obtained results}

In order to determine the values of sample annealing temperature $T_{\mathrm{a}}$ which could have been useful to investigate the character of the influence of thermal conditions on electrical parameters of GaAs in the first stage of presented analysis the dependences of resistivity and capacity on the annealing temperature were plotted for certain values of the sample operating temperatures $T_{\mathrm{p}}$. On this basis it was possible to specify what changes in the internal structure of the tested material are introduced by annealing at the temperature $T_{\mathrm{a}}$ and which cases are eligible for further analysis. In Fig. 1 it can be seen that the increase in the annealing temperature up to $573 \mathrm{~K}$ causes also a slight increase in the values of resistivity, however, the observed growth did not exceed one order of magnitude. For $T_{\mathrm{a}}$ ranging from $573 \mathrm{~K}$ to $663 \mathrm{~K}$, it is possible to notice regular reduction in the $\rho$ values, which are close to $10^{6} \Omega \mathrm{cm}$ for $T_{\mathrm{a}}=663 \mathrm{~K}$. Moreover, it is noticeable that the average value of measured resistivity decreases by three orders of magnitude with the increase in the operating temperature. As a result, for the highest recorded $T_{\mathrm{p}}=373 \mathrm{~K}$ the value of $\rho$ is practically stable in the whole considered range of $T_{\mathrm{a}}$.

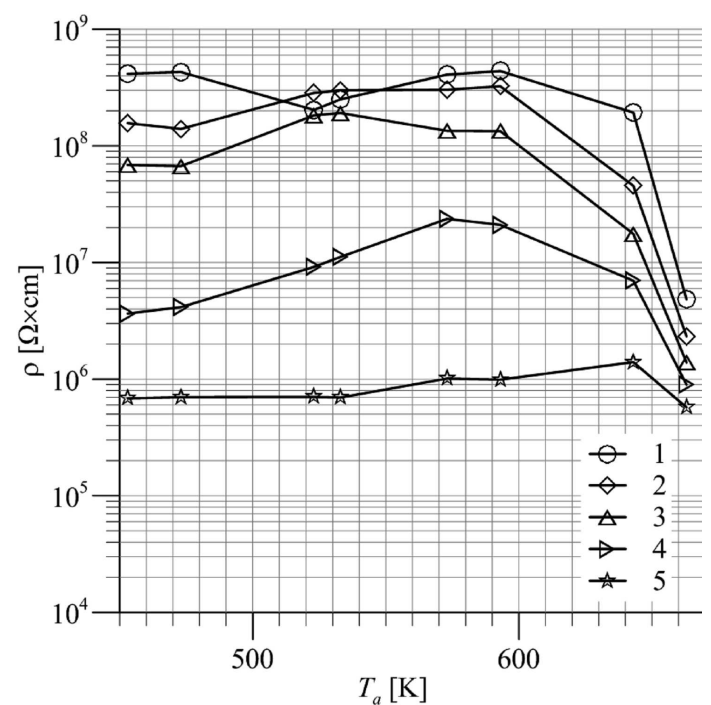

Fig. 1. Dependences $\rho=f\left(T_{\mathrm{a}}\right)$ for the sample of Tedoped GaAs of $\rho=0.55 \Omega \mathrm{cm}$, exposed to poly-energy implantation with $\mathrm{H}^{+}$ions, measured at different operating temperatures $T_{\mathrm{p}}: 1-173 \mathrm{~K}, 2-223 \mathrm{~K}, 3-$ $273 \mathrm{~K}, 4-323 \mathrm{~K}, 5-373 \mathrm{~K}$.

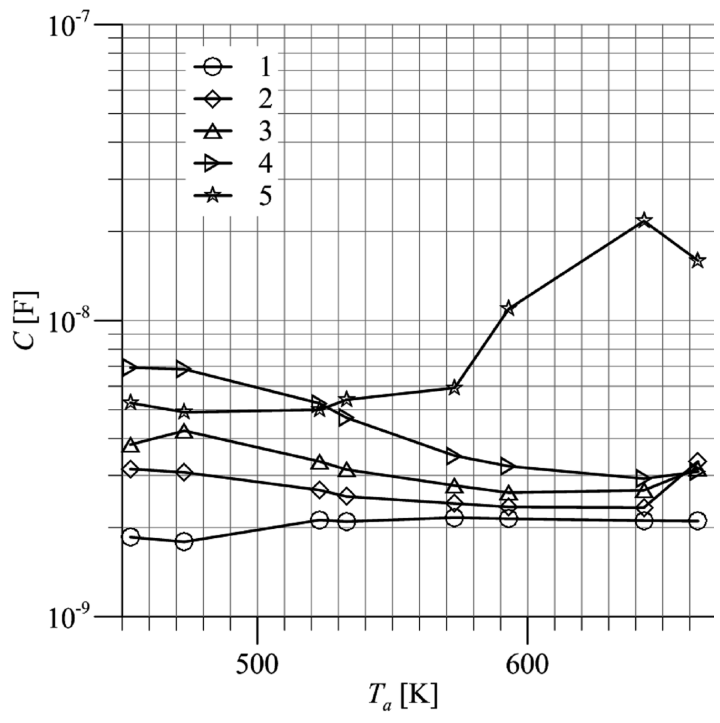

Fig. 2. As in Fig. 1. but for dependences $C=f\left(T_{\mathrm{a}}\right)$.

On the other hand, Fig. 2 shows that the value of capacity is insignificantly affected by changing thermal conditions, as it is possible to observe that for $T_{\mathrm{p}}=173 \mathrm{~K}$ the capacity plot is almost stable, and with the increasing $T_{\mathrm{a}}$ a slight decrease of $C$ value (one order of magnitude) is found for $T_{\mathrm{p}}$ up to $323 \mathrm{~K}$. Exceptionally, for $T_{\mathrm{p}}=373 \mathrm{~K}$ the capacity rises over $T_{\mathrm{a}}=573 \mathrm{~K}$.

The second stage of analysis was performed to confirm the degree of influence of operating temperature on stability of $\rho, C$, and $\tan \delta$ values of tested samples. Figure 3 presents the dependences of resistivity in the function of the operating temperature plotted for values of $T_{\mathrm{a}}$ determined in the previous stage of the analysis. As it can 


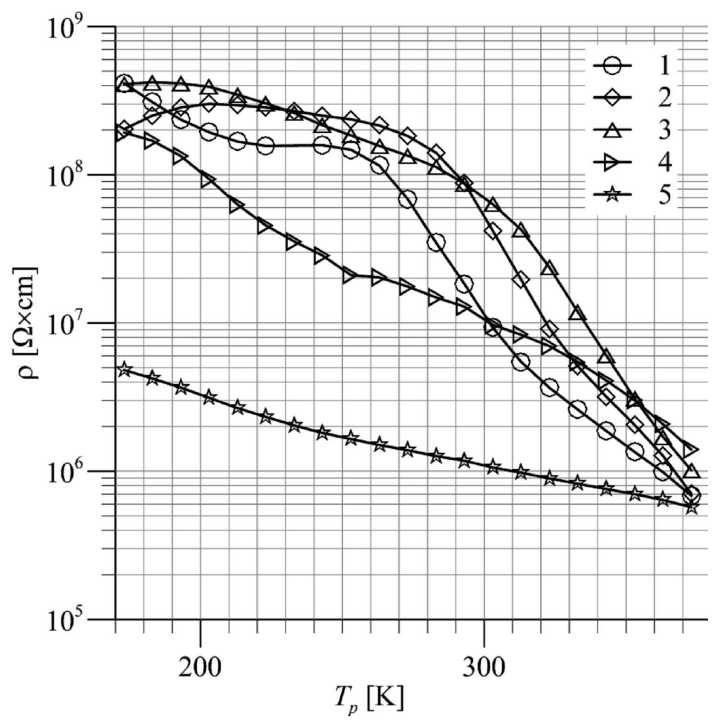

Fig. 3. Dependences $\rho=f\left(T_{\mathrm{p}}\right)$ for the sample of Tedoped GaAs of $\rho=0.55 \Omega \mathrm{cm}$, exposed to poly-energy implantation with $\mathrm{H}^{+}$ions, annealed at different temperatures $T_{\mathrm{a}}: 1-453 \mathrm{~K}, 2-523 \mathrm{~K}, 3-573 \mathrm{~K}$, $4-643 \mathrm{~K}, 5-663 \mathrm{~K}$.

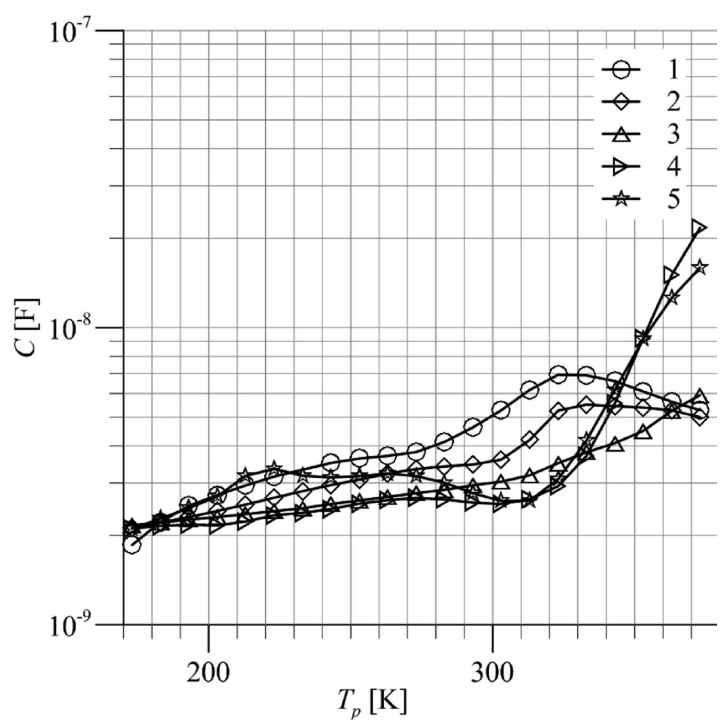

Fig. 4. As in Fig. 3, but for dependences $C=f\left(T_{\mathrm{p}}\right)$.

be seen only annealing at the highest $T_{\mathrm{a}}$ temperature ensures a relatively stable resistivity dependence, opposite to the other registered plots. Analysis of capacity changes (Fig. 4) confirms the tendency towards low sensitivity of its value to the variable thermal treatments as well as operating conditions. A significantly different trend could be observed in the $\tan \delta$ plot presented in Fig. 5. Consequently, one can see that annealing at $T_{\mathrm{a}}=663 \mathrm{~K}$ stabilized the value of the loss tangent on the level of $10^{1}$ in the full range of considered operating temperature, whereas the plots referring to the lower $T_{\mathrm{a}}$ values stabilize after reaching the operating temperature level from $290 \mathrm{~K}$ to $340 \mathrm{~K}$, depending on the value of $T_{\mathrm{a}}$.

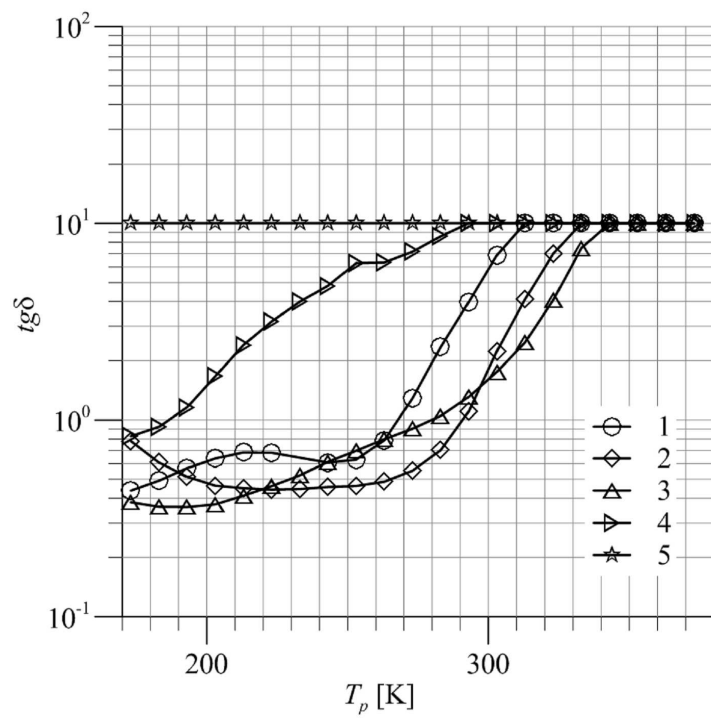

Fig. 5. As in Fig. 3, but for dependences $\tan \delta=$ $f\left(T_{\mathrm{p}}\right)$.

\section{Conclusions}

The obtained results confirmed that there is a strict correlation between the operating and annealing temperatures as well as the abilities to transfer electric charge carriers. The observed correlation could be explained on the basis of the model of jumping recharging mechanism in strongly defected GaAs, which was discusssed in [21], as well as the mechanism of radiation defects creation [22].

Comparative analysis of the temperature dependences presented above, plotted for the poly-energy ionimplanted GaAs samples, was aimed at evaluating ion implantation conditions as well as the implanted samples parameters in the way that ensures high thermal stability rate in the considered range of operating temperatures $T_{\mathrm{p}}$. As a result, it was concluded that in GaAs doped with tellurium, defected by the process of ion implantation and annealed at the temperature up to $663 \mathrm{~K}$ thermal stability of measured parameters was partially achieved. Therefore, it is reasonable to continue the research aimed at choosing such parameters of ion implantation and post-implantation processes that will allow to produce a thermally stable GaAs sample.

\section{References}

[1] National Renewable Energy Laboratory, Research Cell Efficiency Report, U.S. Department of Energy, 2014.

[2] V. Benda, AIP Conf. Proc. 1499, 6 (2012).

[3] T. Markvart, L. Castañer, Practical Handbook of Photovoltaics Fundamentals and Applications, Elsevier Advanced Technology, Oxford 2003.

[4] Handbook of Photovoltaic Science and Engineering, Eds. A. Luque, S. Hegedus, Wiley, Chichester 2011. 
[5] A. Chandra, G. Anderson, S. Melkote, W. Gao, H. Haitjema, K. Wegener, CIRP Annals - Manufact. Technol. 63, 797 (2014).

[6] D. Stievenard, X. Boddaert, J.C. Bourgoin, H.J. von Bardeleben, Phys. Rev B 41, 5271 (1990).

[7] H.H. Tan, J.S. Williams, C. Jagadish, J. Appl. Phys. 78, 1481 (1995).

[8] M. Green, K. Emery, Y. Hishikawa, W. Warta, E. Dunlop, Progr. Photovolt. Res. Appl. 21, 1 (2013).

[9] L. Mattos, S. Scully, M. Syfu, E. Olson, L. Yang, C. Ling, B. Kayes, G. He, in: Photovoltaic Specialists Conference (PVSC), 2012 38th IEEE, IEEE, 2012, p. 003187.

[10] E. Yablonovitch, T. Gmitter, J. Harbison, R. Bhat, Appl. Phys. Lett. 51, 2222 (1987).

[11] B. Kayes, H. Nie, R. Twist, S. Spruytte, F. Reinhardt, I. Kizilyalli, G. Higashi, in: Photovoltaic Specialists

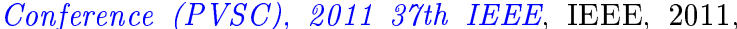
p. 000004 .

[12] T.J. Silverman, M.G. Deceglie, B. Marion, S. Cowley, B. Kayes, S. Kurtz, in: Photovoltaic Specialists Conference (PVSC), 2013 IEEE 39th, IEEE, 2013, p. 0103.

[13] M. Kowalski, J. Partyka, P. Wegierek, P. Żukowski, F.F. Komarov, A.V. Jurchenko, D. Freik, Vacuum 78, $311(2005)$
[14] M. Turek, A. Droździel, K. Pyszniak, D. Mączka, Przeglad Elektrotechniczny 11b, 328 (2012) (in Polish).

[15] M. Turek, A. Drozdziel, K. Pyszniak, S. Prucnal, D. Maczka, Y.V. Yushkevich, Y.A. Vaganov, Instrum. Exp. Tech. 55, 469 (2012).

[16] M. Turek, S. Prucnal, A. Drozdziel, K. Pyszniak, Rev. Sci. Instrum. 80, 043304 (2009).

[17] M. Turek, S. Prucnal, A. Drozdziel, K. Pyszniak, Nucl. Instrum. Methods Phys. Res. B 269, 700 (2011).

[18] M. Turek, A. Droździel, K. Pyszniak, S. Prucnal, J. Żuk, Przeglad Elektrotechniczny 86, 193 (2010) (in Polish).

[19] P. Żukowski, J. Partyka, P. Wegierek, Phys. Status Solidi A 159, 509 (1997)

[20] J. Partyka, P. Żukowski, P. Węgierek, A. Rodzik, Y. Sidorenko, Y. Szostak, Semiconductors 36, 1326 (2002).

[21] P. Zukowski, T. Kołtunowicz, J. Partyka, P. Wegierek, F.F. Komarov, A.M. Mironov, N. Butkievith, D. Freik, Vacuum 81, 1137 (2007).

[22] D. Pons, J.C. Bourgoin, J. Phys. C Solid State Phys. 18, 3839 (1985). 